\title{
Human milk vitamin content after pasteurisation, storage, or tube feeding
}

\author{
D VAN ZOEREN-GROBBEN, J SCHRIJVER, H VAN DEN BERG, AND H M BERGER
}

Neonatal Unit, Department of Paediatrics, University Hospital, Leiden, and Department of Clinical Biochemistry, TNO-CIVO Toxicology and Nutrition Institute, Zeist, The Netherlands

SUMmARY We investigated the effect of the composition of the storage container, Holder pasteurisation, and conditions during tube feeding on the concentration of selected vitamins in human milk. Though the fat soluble vitamins A, D, and E were not affected, the concentration of several water soluble vitamins decreased. The lower vitamin $\mathrm{C}$ concentration of milk stored in polypropylene containers compared with milk stored in glass containers $(29 \%)$ was not significant. Holder pasteurisation significantly lowered the concentrations of vitamins C $(36 \%)$, folacin $(31 \%)$, and $\mathrm{B}_{6}(15 \%)$. Tube feeding significantly lowered the concentrations of vitamins $\mathrm{C}(44 \%)$ and $\mathrm{B}_{6}(19 \%)$, and exposure to phototherapy seemed to lower the vitamin C concentration $(53 \%)$ further.

Low birthweight infants have increased vitamin requirements. Vitamin losses in expressed human milk before or during feeding may increase the incidence of vitamin deficiencies in these babies.

The vitamin concentration of human milk may not satisfy the requirements of the preterm baby. ${ }^{1}$ This problem could be aggravated if vitamin losses occur during pasteurisation and storage of the milk. Vitamin losses due to these factors have been extensively studied in cows' milk ${ }^{2}$ but have received little attention in human milk. ${ }^{13}$

Further losses could occur during feeding due to exposure of the milk to light-for example, phototherapy-and by adsorption of vitamins to the walls of the containers and the tubing of the feeding system. These factors do influence the concentration of vitamins $B_{2}$ and $B_{6}{ }^{4}$ and $A, D$, and $E^{5}$ of parenteral solutions. In human milk only the losses of vitamins $B_{2}$ and $A$ during feeding have been studied. ${ }^{67}$

We therefore studied the influence of pasteurisation, composition of the storage container, and conditions during tube feeding on the concentration of selected vitamins in human milk.

\section{Materials and methods}

Milk samples. Milk was obtained from healthy mothers who were not receiving any medication or vitamin supplements. Their infants had been born at term and breast fed for one to eight months.
Morning specimens were obtained using a hand suction pump (Kaneson ${ }^{R}$, Yanase Waitch, Osaka, Japan) and stored in polypropylene bottles $(120 \mathrm{ml}$ Axifeed $^{\mathrm{R}}$, Mecomfa, Lisse, The Netherlands), wrapped in aluminium foil in a domestic refrigerator $\left(4^{\circ} \mathrm{C}\right)$ after standard instructions. All specimens were transported within four hours in iceboxes to the hospital, where they were immediately combined to make up nine different pools of $160 \mathrm{ml}$. After thorough mixing each pool was divided into five samples and the various treatments begun.

\section{Control sample}

Twenty $\mathrm{ml}$ from each pool were stored in two $10 \mathrm{ml}$ sterile air tight containers, which were completely filled and covered in aluminium foil. The composition of these polypropylene containers was identical to that of the Axifeed bottle. All samples were stored at $-20^{\circ} \mathrm{C}$ for three weeks until analysed. The fat soluble and B vitamin concentrations measured at this time were used as the control values for all experiments, while the vitamin $\mathrm{C}$ concentrations measured at this time were only used as the control value for the experiment on the influence of the composition of the storage container. As vitamin C is unstable ${ }^{8}$ the control sample for the experiments on the influence of pasteurisation, feeding pro- 
cedure, and phototherapy was handled differently: two $\mathrm{ml}$ from each pool were stored in a $2 \mathrm{ml}$ sterile air tight container covered with aluminium foil, containing $2 \mathrm{mg}$ reduced glutathione, at $4^{\circ} \mathrm{C}$ until vitamin $\mathrm{C}$ analysis within 48 hours after the milk collection.

Effect of various treatments. All samples were stored in conditions identical to those of the control samples.

\section{Influence of the composition of the storage container}

Twenty $\mathrm{ml}$ of each pool were stored in two $10 \mathrm{ml}$ sterile air tight glass containers in exactly the same conditions as described for the control sample until vitamin analysis (which included analysis for vitamin C). This allowed us to compare the influence on the vitamin content of storage in the glass with the polypropylene container.

\section{Influence of pasteurisation}

Holder pasteurisation, $62.5^{\circ} \mathrm{C}$ for 30 minutes, was performed on samples of $50 \mathrm{ml}$ of each pool in sterile air tight polypropylene bottles (Axifeed) according to the recommendations of the Department of Health and Social Security. ${ }^{9}$ Preliminary studies showed that our system warmed the milk samples to $62 \cdot 5^{\circ} \mathrm{C}$ within eight minutes and subsequently cooled them to $20^{\circ} \mathrm{C}$ within five minutes. In this experiment two samples were discarded after a technical failure resulted in a prolonged heating period.

\section{Losses during feeding}

The feeding procedure used for low birthweight infants was imitated. A $20 \mathrm{ml}$ sample of each pool was drawn up into a $20 \mathrm{ml}$ sterile polypropylene syringe (Once, Asik, Denmark) and pumped at a rate of $4 \mathrm{ml} /$ hour through $180 \mathrm{~cm}$ of polyvinylchloride (PVC) connecting tubing (Talas, Ommen, The Netherlands) and a $100 \mathrm{~cm} 5$ charriere PVC feeding tube (Unoplast, Denmark) into a sterile polypropylene container protected from light by aluminium foil. The syringe, with an eccentric nozzle, was held at an angle of $30^{\circ}$ to prevent accumulation of fat in the syringe. ${ }^{10}$ During the infusion time of five hours the system was exposed to the normal fluorescent lighting and temperature $\left(28^{\circ} \mathrm{C}\right)$ of our neonatal unit.

\section{Losses during feeding and phototherapy}

Using the same infusion system as described above, the milk was also exposed to phototherapy for half an hour by running $100 \mathrm{~cm}$ of the connecting tubing through an incubator $\left(32^{\circ} \mathrm{C}\right)$ placed under a phototherapy unit (four blue lamps Philips TL 20W/52 and four Sylvania daylight lamps F20 WID-RS, $35 \mathrm{~cm}$ above the tubing system).

Vitamin analysis. The following vitamins were measured by high performance liquid chromatographic methods. Vitamins A (all-transretinol) ${ }^{11}$ and $E$ ( $\alpha$-tocopherol $)^{12}$ were determined after alkaline saponification and vitamins $B_{2}$ and $B_{6}$ were analysed as their biologically active cofactors, flavin adenine dinucleotide ${ }^{13}$ and pyridoxal $5^{\prime}$-phosphate, ${ }^{14}$ respectively. Vitamin $\mathrm{C}$ was measured as $\mathrm{L}$-ascorbic acid plus dehydro-L-ascorbic acid. ${ }^{8}$

The vitamin $B_{12}$ content was measured by competitive protein binding assay using purified intrinsic factor (Sigma Chemical Company, St Louis, Missouri, United States). ${ }^{15}$ Vitamin $\mathrm{B}_{12}$ was extracted in boiling $0 \cdot 1 \mathrm{M}$ sodium acetate buffer $(\mathrm{pH} 4.8)$ containing $0.005 \%$ (weight/volume) potassium cyanide $\left(15\right.$ minutes at $\left.100^{\circ} \mathrm{C}\right)$. To reduce nonspecific binding in the competitive protein binding assay, which is observed with milk samples using only acetate extraction, an alkaline denaturation step ( 20 minutes at $37^{\circ} \mathrm{C}$ in $0 \cdot 1 \mathrm{M}$ sodium hydroxide) was performed before acetate extraction.

The folacin content was estimated as the 'free' 5methyltetrahydrofolic acid (5-MeTHF) content by radioassay using purified folate binding protein (Sigma Chemical Company) as binder. ${ }^{16}$ 5-MeTHF purified on reversed phase high performance liquid chromatography was used as the standard and tritiated pteroylmonoglutamic acid as the tracer. Milk folates were extracted in a boiling $0 \cdot 2 \mathrm{M}$ borate buffer ( $\mathrm{pH} \mathrm{9.3)} \mathrm{containing} \mathrm{1 \%} \mathrm{(weight/volume)}$ freshly added vitamin $\mathrm{C}$. The presence of polyglutamate forms of 5-MeTHF may result in a slight overestimation of the free folacin content using a radioassay. ${ }^{17}$

Vitamin D was quantitated as the 25hydroxyvitamin D (25-OHD) present in the lipid extract, which accounts for at least $75 \%$ of its antirachitic activity present in human milk. The 25OHD content in the total lipid extract was quantitated by competitive protein binding assay, ${ }^{18}$ but before the assay the extract was purified by straight phase high performance liquid chromatography.

Statistical analysis. Evaluation of the results was performed using the paired $t$ test with the help of the department of statistics (Dr T Stijnen). To correct for multiple comparisons only $p$ values $<0.01$ were regarded as significant.

\section{Results}

The composition of the storage container (Table 1) 
Table 1 Differences in vitamin concentrations of human milk stored in polypropylene or glass containers. Values are mean (SD) [range]

\begin{tabular}{|c|c|c|c|c|c|c|}
\hline Vitamin & $n$ & Polypropylene & & Glass & & \\
\hline A $(\mu \mathrm{mol} / \mathrm{l})$ & 9 & $1.32(0.83)$ & {$[0 \cdot 50-3 \cdot 15]$} & 1.39 & $(0.84)$ & {$[0.54-3 \cdot 25]$} \\
\hline $\mathrm{D}(\mathrm{pmol} / \mathrm{l})$ & 8 & $143 \quad(64)$ & $|68-26(1)|$ & 149 & (59) & $|7 x-252|$ \\
\hline $\mathrm{B}_{2}(\mu \mathrm{mol} / \mathrm{l})$ & 9 & $(0.59(0.16)$ & {$[(0.35-(0) .87]$} & 0.57 & $(0.16)$ & {$[(1.34-0.81]$} \\
\hline $\mathrm{B}_{6}(\mathrm{nmol} / \mathrm{l})$ & 9 & (36) & {$[37-156]$} & 90 & $(37)$ & $\mid 39-161]$ \\
\hline $\mathrm{B}_{12}(\mathrm{pmol} / \mathrm{l})$ & 8 & (133) & $|157-523|$ & 297 & $(128)$ & $|149-501|$ \\
\hline Folacin $(\mathrm{nmol} / \mathrm{l})$ & 8 & (24) & $|42-110|$ & 73 & $(25)$ & $|40-112|$ \\
\hline
\end{tabular}

Table 2 Influence of pasteurisation, tube feeding, and phototherapy on vitamins in human milk

\begin{tabular}{llcl}
\hline Vitamin & \multicolumn{2}{l}{ Mean (SD) \% remaining after } \\
\cline { 2 - 4 } & Pasteurisation & Tube feeding & $\begin{array}{l}\text { Tube feeding } \\
+ \text { phototherapy }\end{array}$ \\
\hline $\mathrm{A}$ & & & $102(19)$ \\
$\mathrm{D}$ & $103(15)$ & $94(19)$ & $100(8)$ \\
$\mathrm{E}$ & $103(10)$ & $101(14)$ & $100(12)$ \\
$\mathrm{B}_{2}$ & $1(16(13)$ & $100(13)$ & $97(2)$ \\
$\mathrm{B}_{6}$ & $94(8)$ & $98(7)$ & $83(11)^{*}$ \\
$\mathrm{~B}_{12}$ & $85(8)^{* *}$ & $81(12)^{* *}$ & $101(7)$ \\
Folacin & $90(10)$ & $97(6)$ & $110(17)$ \\
$\mathrm{C}$ & $69(8)^{* *}$ & $99(12)$ & $47(22)^{* *}$ \\
\hline
\end{tabular}

${ }^{*} \mathrm{p}<0 \cdot(01 ;$

${ }^{* *} \mathrm{p}<0 \cdot(0) 1$.

only affected the vitamin $\mathrm{C}$ concentration, which was $29 \%$ lower in the milk in the polypropylene containers compared with the milk in the glass containers. The fall in the vitamin $\mathrm{C}$ concentration was not significant $(\mathrm{p}=0 \cdot 02)$.

Pasteurisation (Table 2) did not influence the concentrations of vitamins $A, D, E, B_{2}$, and $B_{12}$. There were, however, significant losses of vitamins $\mathrm{B}_{6}(15 \%), \mathrm{C}(36 \%)$, and folacin $(31 \%)$.

Delivery of the milk through a feeding system (Table 2) lowered the vitamin $C$ and vitamin $B_{6}$ concentrations by $44 \%$ and $19 \%$, respectively. Additional exposure of the milk in the tubing to phototherapy (Table 2) resulted in a similar fall in the vitamin $\mathrm{B}_{6}$ concentration $(17 \%)$ and a slightly greater fall in the vitamin $\mathrm{C}$ concentration $(53 \%)$.

\section{Discussion}

Our study shows that the composition of the storage container, pasteurisation, and conditions during tube feeding can lower the vitamin content of human milk.

Plastic containers are preferred for storing fresh human milk because leucocytes are lost by adherence to the wall of glass containers. ${ }^{19}$ Plastic containers, however, may adsorb vitamins onto their walls. In parenteral solutions vitamins A, D, and $\mathrm{E}$ are lost by adsorption to plastic. ${ }^{5} \mathrm{We}$ found that the concentrations of the vitamins $A, D, E, B_{2}$, $B_{6}, B_{12}$, and folacin were the same when the milk was stored by polypropylene containers compared with storage in glass containers. The lower vitamin $\mathrm{C}$ concentration in the polypropylene container was not regarded as significant in our study because of the multiple statistical comparisons performed. These findings are, however, being followed up.

In addition to the influence that the composition of the containers has on the vitamin concentrations of human milk, the duration and the temperature of storage may influence the vitamin concentrations too. This is well known for vitamin $\mathrm{C}^{720}$ and was taken into account in our study. Recently, however, Bank et al have shown that folacin concentrations may also fall in stored human milk, ${ }^{20}$ although this was not found in a previous study. ${ }^{21}$ Concentrations of other vitamins may also be unstable in human milk. We intended to study the vitamin content of our samples after three months' storage, but unfortunately lost all these samples due to refrigeration failure.

Holder pasteurisation is used by many milkbanks. Although its influence on the immunological components ${ }^{22}$ and macronutrients has been studied, its influence, however, on vitamin concentrations has received little attention. We observed a significant decrease in vitamin $B_{6}$ concentrations, while vitamin $A, D, E, B_{2}$, and $B_{12}$ concentrations remained stable, similar to the findings in cows' milk. ${ }^{2}$ The observed decrease of vitamin $B_{6}$ may, however, have been the result of hydrolysis to its non-phosphorylated forms pyridoxal. The decrease of the vitamins $\mathrm{C}(36 \%)$ and folacin $(31 \%)$ was greater than has been reported for cows' milk $(20 \%$ and $10 \%$, respectively). ${ }^{2}$ Other methods of heat treatment using a shorter time ${ }^{3}$ or a lower temperature ${ }^{23}$ might be preferable. Goldblum et al found no decline of vitamin $B_{1}, B_{2}, B_{6}, C$, and folacin concentrations with rapid high temperature treatment. ${ }^{3}$ Ford et al have already pointed out that 
Holder pasteurisation of human milk decreases the bioavailability of certain vitamins-for example, folacin-by damaging their binding proteins. ${ }^{22}$

Vitamin losses from banked human milk may also occur during feeding because of photo-oxidation ${ }^{6}$ or by adsorption to the tubing used. ${ }^{7}$ We only found a significant loss of vitamins $B_{6}$ and $C$. Addition of phototherapy did not affect the vitamin losses except for a small increase in the loss of vitamin C. Previous studies with parenteral solutions showed a decrease in vitamins $B_{2}$ and $B_{6}$ due to photooxidation ${ }^{4}$ and $\mathrm{A}, \mathrm{D}$, and $\mathrm{E}$ due to adsorption to the feeding system. ${ }^{5}$

In enteral feeding only vitamins $A$ and $B_{2}$ had previously been studied: Bryant et al found no decrease of vitamin $A$ in feeding formula ${ }^{24}$ and Bates et al found a decrease of vitamin $A$ and $B_{2}$ in drip human milk, which they suggested was due to photo-oxidation. ${ }^{6}$ The discrepancies between these findings and ours need an explanation. In the parenteral solutions studied no fat or proteins were present and in human milk binding of vitamins $A$, $\mathrm{D}$, and $\mathrm{E}$ to these substances may limit adsorptive losses. The higher fat content of the expressed human milk used in our study may also have limited the penetration of light into the milk and prevented the vitamin $A$ and $B_{2}$ losses due to photo-oxidation found by Bates et al in their study using drip milk, ${ }^{6}$ which has a lower fat content. Furthermore, in the study of Bates et al the exposure time to phototherapy was much longer than in our study (six hours as against half an hour). Vitamins $B_{6}$ and $C$ had not been studied previously in human milk, but studies in parenteral feeding ${ }^{4}$ and cows' milk have shown that these vitamins are particularly sensitive to photo-oxidation. In our study we tried to imitate two feeding methods often used for low birthweight infants. Further studies are needed to investigate which of the factors present in these situations-for example, exposure time, intensity and wavelength of light, or environmental temperature-are the most important. It is also important to realise that photo-oxidative losses during collection of milk by the mother or preparation of feeds in the neonatal unit could also occur.

In conclusion, we found a significant decrease of several vitamins in human milk during storage (vitamin $\mathrm{C}$ ), pasteurisation (vitamins $\mathrm{B}_{6}$, folacin, and $\mathrm{C}$ ), and delivery through a tubing system (vitamins $B_{6}$ and $C$ ). These losses could accumulate as in routine use the milk passes through all these stages.

The low birthweight infant is born with marginal reserves of fat soluble vitamins and may require more water soluble vitamins. ${ }^{1}$ It seems that routinely used methods for processing and feeding human milk to low birthweight babies do not influence the concentration of fat soluble vitamins but do lower the concentration of water soluble vitamins. Supplementation with water soluble vitamins may be necessary when the low birthweight infant is fed with expressed human milk.

We thank the mothers for providing the milk samples, Mrs $\mathrm{J}$ Caljouw of La Lèche League for her help, and Mrs I Haasnoot, J Ferrari, and $M$ Silverentand for their technical help.

\section{References}

${ }^{1}$ Tsang RC. Vitamin and mineral requirements in preterm infants. New York: Marcel Dekker, 1985.

2 Causeret J. La valeur vitaminique des laits animaux. Comparaison avec celle du lait de femme. Annales de la Nutrition et de l'Alimentation 1971;25:313-34.

${ }^{3}$ Goldblum RM, Dill CW, Albrecht TB, Alford ES, Garza C, Goldman AS. Rapid high-temperature treatment of human milk. J Pediatr 1984;104:380-5.

${ }^{4}$ Chen MF, Worth Boyce H, Triplett L. Stability of the B vitamins in mixed parenteral nutrition solution. JPEN 1983;7:462-4.

${ }^{5}$ Gillis J, Jones G, Pencharz P. Delivery of vitamins A, D and E in total parenteral nutrition solutions. JPEN 1983;7:11-4.

${ }^{6}$ Bates CJ, Liu D-S, Fuller NJ, Lucas A. Susceptibility of riboflavin and vitamin $\mathrm{A}$ in breast milk to photodegradation and its implications for the use of banked breast milk in infant feeding. Acta Paediatr Scand 1985;74:40-4.

${ }^{7}$ Garza C, Johnson CA, Harrist R, Nichols BL. Effects of methods of collection and storage on nutrients in human milk. Early Hum Dev 1982;6:295-303.

${ }^{8}$ Speek AJ, Schrijver J, Schreurs WHP. Fluorometric determination of total vitamin $\mathrm{C}$ in whole blood by high-performance liquid chromatography with precolumn derivatization. J Chromatogr 1984;303:53-60.

9 Department of Health and Social Security, Panel on Child Nutrition.The collection and storage of human milk. Working party report on human milk banks. London: HMSO, 1981:29-31. (Report on health and social subjects No 22.)

10 Narayanan I, Singh B. Harvey D. Fat loss during feeding of human milk. Arch Dis Child 1984;59:475-7.

"De Ruyter MG, De Leenheer AP. Determination of serum retinol levels (vitamin A) by high-speed liquid chromatography. Clin Chem 1976;22:1593-5.

12 Speek AJ, Schrijver J, Schreurs WHP. The vitamin E composition of some seed oils as determined by high-performance liquid chromatography with fluorometric detection. J Food Sci 1985;50:121-4.

13 Speek AJ, Van Schaik F, Schrijver J, Schreurs WHP. Determination of the $B_{2}$ vitamin flavin adenine dinucleotide in whole blood by high-performance liquid chromatography with fluorometric detection. J Chromatogr 1982;228:311-6.

14 Schrijver J, Speek AJ, Schreurs WHP. Semi-automated fluorometric determination of pyridoxal-5'-phosphate (vitamin $\mathrm{B}_{6}$ ) in whole blood by high-performance liquid chromatography (HPLC). Int J Vitam Nutr Res 1981;51:216-22.

15 Richardson PJ, Favell DJ, Gidley GL, Jones GH. Application of a commercial radioassay kit to the determination of vitamin $\mathrm{B}_{12}$ in food. Analyst 1978;103:865-8.

16 Graham DC. Roe DA. Ostertag SG. Radiometric determination and chick bioassay of folacin in fortified and unfortified frozen foods. J Food Sci 1982;45:47-51.

17 Shane B, Tamura T, Stokstad ELR. Folate assays: a comparison of radioassay and microbiological methods. Clin Chim Acta 1980;100:13-9. 
${ }^{18}$ Edelstein J, Charman M, Lawson DEM, Kodicek E. Competitive protein binding assay for 25-hydroxy cholecalciferol. Clinical Science and Molecular Medicine 1974;46:231-40.

${ }^{19}$ Paxson CL, Cress CC. Survival of human milk leucocytes. J Pediatr 1979:94:61-4.

20 Bank MR, Kirksey A, West K, Giacoia G. Effect of storage time and temperature on folacin and vitamin $C$ levels in term and preterm human milk. Am J Clin Nutr 1985;41:235-42.

${ }^{21}$ Friend BA, Shahani KM, Long CA, Vaughn LA. The effect of processing and storage on key enzymes, B vitamins, and lipids of mature human milk. I Evaluation of fresh samples and effects of freezing and frozen storage. Pediatr Res 1983;17:61-4.

${ }^{22}$ Ford JE, Law BA, Marshall VME, Reiter B. Influence of the heat treatment of human milk on some of its protective constituents. J Pediatr 1977;90:29-35.

23 Wills ME, Han VEM, Harris DA, Baum JD. Short-time lowtemperature pasteurisation of human milk. Early Hum Dev 1982;7:71-80.

${ }^{24}$ Bryant CA, Neufeld NJ. Differences in vitamin A content of enteral feeding solutions following exposure to a polyvinyl chloride enteral feeding system. JPEN 1982;6:403-5.

Correspondence to Dr D van Zoeren-Grobben, Department of Paediatrics, University Hospital, Building 35, Postbus 9600, 2300 RC Leiden, The Netherlands.

Received 1 September 1986 